\title{
STUDY OF FATIGUE CRACK GROWTH IN 6063-T6 ALUMINUM ALLOY
}

\author{
Nirpesh Vikram \\ BBDNIIT, Lucknow, India \\ E-mail: nirpesh.vikram@gmail.com \\ Raghuvir Kumar \\ BBDNIIT, Lucknow, India \\ E-mail: rkg@mnnit.ac.in \\ Submission: 08/06/2015 \\ Revision: 03/07/2015 \\ Accept: 12/07/2015
}

\section{ABSTRACT}

The present study relates to investigate the crack propagation behavior of 6063 T6 Al Aluminum Alloy under fatigue loading. The experimental as well as analytical analysis was done and for crack growth rate for 6063-T6 Aluminum Alloy. All analysis was done on Side edge notch specimen. A program was developed on Matlab $₫$ to calculate crack growth rate and effective stress intensity range ratio based on polynomial algorithm. That gave a very good agreement between them. The effective stress intensity range ratio $(U)$ was found to depend on stress ratio (R). Variation in load range affects the crack growth rate. For constant load range its variation was negligible, constant $\mathrm{C}$ was almost constant at variable load range. Variation of maximum load affects constant $\mathrm{C}$.

Keywords: Fatigue, 6063-T6 Al Alloy, Fracture, Analytical Analysis, Crack Closure 


\section{INTRODUCTION}

The phenomenon of metal fatigue is very old and is related with mechanical failure of the components subjected to cyclic loading. Fatigue failure is a major problem encountered by designers. Generally it occurs in the machine components and structures which are associated with dynamic loading i.e. the load on a component changing with time. Although fatigue failure is important in almost all the design problems, yet the designing of the components of some machines like an aircraft, space vehicle, turbine, engine, rails \& bridges are most critical (BROEK, 1982; ZHENG, 1983; ELBER, 1970).

According to ASTM (1976) fatigue is defined as "the process of progressive localized permanent structural change occurring in the material subjected to the conditions which produce fluctuating stresses and strain at some point or points and which may culminate in crack or complete fracture after a sufficient number of fluctuations" (FOREMAN; MEARNEY; ENGLE ,1967; WALKER, 1970; NIRPESH; RAGHUVIR, 2013; NIRPESH; RAGHUVIR, 2015).

Fatigue failures are generally caused due to some stress raisers as a crack initiates from these stress raisers. (PEARSON, 1972; ELBER, 1971; NIRPESH; SAKSHI; RAGHUVIR, 2014) There are three most important factors which cause the fatigue failure to take place:

- $\quad$ Cyclic loading

- Points of stress concentration

- $\quad$ Residual tensile stresses

\section{METHOD}

The crack growth rate experiments have been carried out by various researchers on a wide range of materials using different specimen geometries (PARIS; ERDOGAN, 1963; BROEK, 1982; ZHENG, 1983; ELBER, 1970; NICCOLLS, 1976; KUMAR; GARG, 1988A; KUMAR; GARG, 1988B; ASTM, 1967). 
Studies have shown that the crack propagation is a complex phenomenon. Literature reveals that crack growth rate (CGR) can be related to $\Delta \mathrm{K}, \Delta \mathrm{K}_{\ominus}$ etc. these relationships are empiricalin nature. The CGR constants $\mathrm{C}, \mathrm{m}$ etc. of different models are considered to be material constants. In addition to materials they depend upon loading parameters $\Delta \sigma, \sigma_{\mathrm{m}}$ and $R$.

A number of researchers tried to relate these constants with the loading parameters for 6061-T6 and 6063-T6 Aluminum alloys.

Here are the main steps of the work carried out:

(1) A program is written using MAT Lab to calculate the maximum stress intensity factor $K_{m}$, stress intensity range $\Delta K$, effective stress intensity range $\Delta K_{\ominus}$ and crack growth rate $\frac{d a}{d x}$.

(2) The program thus developed is used on different sets of data (a-N) for 6061-T6 \& 6063-T6 alloys. There is two types of data:

(a) When maximum load was kept constant

(b) When load range was kept constant

$$
\frac{d a}{d N} \quad \frac{d a}{d N} \quad \frac{d a}{d N}
$$

(3) The curves are plotted for $\mathrm{N} V s$ a, $N$ Vs , $\Delta \mathrm{K} V s$ and $\Delta \mathrm{K} \Theta V s$, for both the materials.

(4) The constants of the crack growth rate are evaluated for the following models:
(a) Paris and Erdogan model
(b) Elber model
(c) Walker model
(d) Foreman model

(5) Co-relations are developed between CGR constants and loading parameters.

\section{ANALYSIS}


The aim of our study is to see the effect of loading parameters on the crack growth rate constants. The first thing is to fit the models in our data and evaluate the constants. It was planned to analysis models for the given type of loading conditions.

1. Maximum load was kept constant and the load ratios were increased.

2. Load range was kept constant and load ratios were increased.

\subsection{Materials used}

The material used is 6063-T6 Al alloys. The chemical composition of the materials as per manufacturer's catalogue is given in Table no (1).

Table 1: Chemical composition of the material

\begin{tabular}{|c|c|c|c|c|c|c|c|}
\hline \multicolumn{2}{|c|}{ Materials } & \multicolumn{6}{|c|}{ Elements } \\
\cline { 3 - 8 } & $\mathrm{Cu}$ & $\mathrm{Mg}$ & $\mathrm{Si}$ & $\mathrm{Fe}$ & $\mathrm{Mn}$ & Others \\
\hline $\begin{array}{c}\text { 6063- } \\
\text { T6 }\end{array}$ & Max & 0.10 & 0.90 & 0.8 & 0.70 & 0.60 & 0.4 \\
\cline { 2 - 8 } & Min & - & 0.40 & 0.30 & - & - & - \\
\hline
\end{tabular}

Table 2: Mechanical properties of the materials

\begin{tabular}{|c|c|c|c|c|c|c|}
\hline \multirow[b]{2}{*}{ Material } & \multicolumn{6}{|c|}{ Properties } \\
\hline & $\begin{array}{l}\sigma_{\mathrm{y}} \\
\mathrm{kg} / \mathrm{mm}^{2}\end{array}$ & $\begin{array}{l}\sigma_{\mathrm{u}} \\
\mathrm{kg} / \mathrm{mm}^{2}\end{array}$ & $\begin{array}{l}\sigma_{\mathrm{f}} \\
\mathrm{kg} / \mathrm{mm}^{2}\end{array}$ & $\begin{array}{l}\mathrm{Ex} 10^{6} \\
\mathrm{~kg} / \mathrm{mm}^{2}\end{array}$ & $\begin{array}{l}\text { Elongation } \\
\%\end{array}$ & $\begin{array}{l}\text { Red } \\
\text { uctio } \\
\mathrm{n} \text { in } \\
\text { area } \\
\%\end{array}$ \\
\hline 6063-Т6 & 14.95 & 18.26 & 33.62 & 5.12 & 10.7 & $\begin{array}{l}45.6 \\
7\end{array}$ \\
\hline
\end{tabular}

\subsection{Fatigue tests}

6063-T6 Al-alloy

1. $P_{m}=820 \mathrm{Kg}$

2. $\Delta \mathrm{P}=585 \mathrm{Kg}$

The details of the experiments are given in Table no (3).

There are 9 experiments in all; tests $\mathrm{S1}$ - S5 were conducted by keeping maximum load constant. Remaining S6-S9, were conducted at constant load range.

Fatigue tests were carried out on the side edged notched specimens of about $180 \mathrm{~mm} \times 50 \mathrm{~mm} \times 3 \mathrm{~mm}$ initially with a notch of $6 \mathrm{~mm}$. During the tests crack initiated 
from this edge readings of number of cycles were taken at a regular interval of $0.5 \mathrm{~mm}$ crack length.

Table 3

\begin{tabular}{|c|c|c|c|c|c|c|}
\hline \multicolumn{7}{|c|}{ Tests for 6063-T6 Al-Alloys } \\
\hline S.No & Tests & $\mathrm{R}$ & $\mathrm{P}_{\mathrm{m}} \mathrm{Kg}$ & $\mathrm{P}_{\mathrm{n}} \mathrm{Kg}$ & $\begin{array}{c}\Delta \mathrm{P} \\
\mathrm{Kg}\end{array}$ & $\mathrm{N}_{\mathrm{f}}$ \\
\hline 1. & $\mathrm{~S} 1$ & 0.0 & 820 & 0 & 820 & 61470 \\
\hline 2. & $\mathrm{~S} 2$ & 0.2 & 820 & 164 & 656 & 83380 \\
\hline 3. & $\mathrm{~S} 3$ & 0.3 & 820 & 246 & 574 & 116000 \\
\hline 4. & $\mathrm{~S} 4$ & 0.35 & 820 & 287 & 533 & 137660 \\
\hline 5. & $\mathrm{~S} 5$ & 0.45 & 820 & 369 & 541 & 199760 \\
\hline 6. & $\mathrm{~S} 6$ & 0 & 585 & 0 & 585 & 479690 \\
\hline 7. & $\mathrm{~S} 7$ & 0.2 & 731.25 & 146.25 & 585 & 143030 \\
\hline 8. & $\mathrm{~S} 8$ & 0.4 & 975 & 390 & 585 & 96990 \\
\hline 9. & $\mathrm{~S} 9$ & 0.6 & 1462.5 & 877.5 & 585 & 76970 \\
\hline
\end{tabular}

\subsection{Program development}

A program was developed for calculating the crack growth rate, maximum stress intensity factor, stress intensity range and effective stress intensity range, which were later used for model fitting.

Following data was used as input in the program, which is written in MATLAB R2012a:

1. No of readings of $(\mathrm{a}-\mathrm{N})$ in a set $\mathrm{N}_{\mathrm{p}}$

2. Crack length (a).

3. Number of cycles $(\mathrm{N})$

4. Maximum load of the cycle $\left(P_{m}\right)$

5. Minimum load of the cycle $\left(P_{n}\right)$

6. Width of the specimen (w)

First we calculate (R) \& (U) (FOREMAN; MEARNEY; ENGLE ,1967;

PEARSON, 1972) 
DOI: 10.14807/ijmp.v6i4.343

$$
\begin{gathered}
R=\frac{P_{n}}{P_{m}} \\
U=0.69+0.5 R+0.12 R^{2}
\end{gathered}
$$

To find out the crack growth rate "seven point successive incremental polynomial method" was adopted. Following form of equation was formed:

$$
\begin{aligned}
& a_{1}=d_{1}+d_{2} N_{1}+d_{2} N_{1}^{2}+d_{4}^{d_{4}} N_{1}^{8}+d_{8}^{d_{8}} N_{1}^{4}+d_{6} N_{1}^{\varepsilon}+d_{7} N_{1}^{7}
\end{aligned}
$$

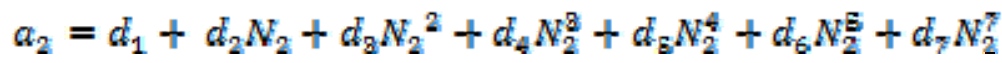

$$
\begin{aligned}
& a_{\mathrm{a}}=d_{1}+d_{2} N_{\mathrm{g}}+d_{\mathrm{g}} N_{\mathrm{g}}^{2}+d_{4} N_{\mathrm{a}}^{2}+d_{\mathrm{g}} N_{\mathrm{a}}^{4}+d_{6} N_{\mathrm{g}}^{\mathrm{E}}+d_{7} N_{\mathrm{g}}^{7} \\
& a_{4}=d_{4}+d_{2}^{l_{2}} N_{4}+d_{2}^{l_{2}} N_{4}^{2}+d_{4} N_{4}^{8}+d_{8} N_{4}^{4}+d_{6}^{l_{6}} N_{4}^{E}+d_{7} N_{4}^{7}
\end{aligned}
$$

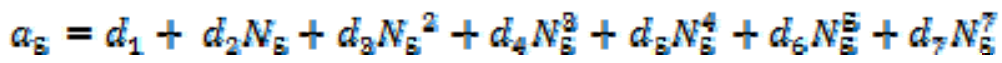

$$
\begin{aligned}
& a_{6}=d_{1}+d_{2} N_{6}+d_{8} N_{6}^{2}+d_{4} N_{6}^{8}+d_{8} N_{6}^{4}+d_{6} N_{6}^{8}+d_{7} N_{6}^{7} \\
& a_{7}=d_{1}+d_{2} N_{7}+d_{8}^{d_{2}} N_{7}^{2}+d_{4}^{d_{4}} N_{7}^{8}+d_{8}^{d_{8}} N_{7}^{4}+d_{6} N_{7}^{5}+d_{7}^{l_{7}} N_{7}^{7}
\end{aligned}
$$

The general form of the equation is as follows:

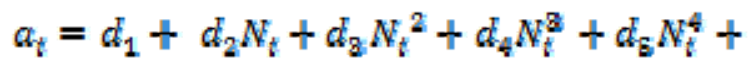
$d_{6}^{1} N_{i}^{\varepsilon}+d_{7}^{l} N_{t}^{7}$

The basic principal to solve these equations is the Gauss elimination method back substitution is used to solve them. For each set of seven readings values was found of constants $d_{1}-d_{7}$ which gave the value of crack growth rate $(d a / d N)$

$$
\begin{aligned}
& \frac{d a}{d N}=d_{2}^{2}+2 d_{8}^{l_{2}} N_{i}+3 d_{4} N_{i}^{2}+4 d_{8}^{l_{8}} N_{i}^{8}+ \\
& 5 d_{6} N_{i}^{4}+6 d_{7} N_{i}^{8}
\end{aligned}
$$

After calculating the first value of crack growth rate, da/dN value was increased from $0-1$ to $2-8$ and the above process repeated for second value of da/dN. Thus calculated the values of da/dN until $i=N_{p}$. here $N_{p}$ is the number of reading in a test. 
For calculating maximum stress intensity factor $\mathrm{K}_{\mathrm{m}}$, stress intensity range $\Delta \mathrm{K}_{\mathrm{e}}(\mathrm{U} \Delta \mathrm{K})$ following equations were used:

$$
\begin{aligned}
& K_{m}=\left(\frac{B_{m}}{A}\right)(a)^{\frac{2}{2}}\{f\} \\
& \Delta K=\left(\frac{\Delta B}{A}\right)(a)^{\frac{3}{2}}\{f\} \\
& \Delta K_{e}=U(\Delta R)
\end{aligned}
$$

Where

$$
\begin{gathered}
f=\left[1.99-0.41\left(\frac{a}{w}\right)+18.7\left(\frac{a}{w}\right)^{2}-\right. \\
\left.38.48\left(\frac{a}{w}\right)^{8}+53.85\left(\frac{a}{w}\right)^{4}\right] \Delta K_{e}=U(\Delta K)
\end{gathered}
$$

Output of the program is given as follows:

1. Stress intensity range ratio $(U)$

2. Maximum stress intensity factor $\left(K_{m}\right)$.

3. Stress intensity range $(\Delta K)$.

4. Effective stress intensity range $\left(\Delta \mathrm{K}_{\mathrm{e}}\right)$

\subsection{Curves drawing}

Computer program was run for various test data. From the output curves were drawn. The scheme of the curves is given below.
(a) Number of cycles Vs Crack length
(b) Number of cycles Vs crack growth rate.
(c) Stress intensity range Vs crack growth rate.
(d) Effective stress intensity range Vs crack growth rate.

A. Maximum load constant

1. N Vs a

2. $N$ Vs CGR

3. $\log \Delta K$ Vs log CGR 
4. $\log \Delta \mathrm{K}_{\mathrm{e}} \mathrm{Vs} \log \mathrm{CGR}$

B. Load range constant

1. $\mathrm{N} V \mathrm{~s}$ a

2. N Vs CGR

3. Log $\Delta \mathrm{K}$ Vs log CGR

4. $\log \Delta \mathrm{K}_{\mathrm{e}} \mathrm{Vs} \log \mathrm{CGR}$

\subsection{Model fitting}

\subsubsection{Model fitting for 6063- T6 Aluminum alloy:}

It is also carried in the two stages i.e.
(A) Maximum load constant
(B) Load range constant.

(A) Maximum load constant: From Figure 1 and 2 we observed that with increasing load ratios life of components and crack initiation stage increased while the crack growth rate decreased.

$\Delta \mathrm{K}$ Vs CGR \& $\Delta \mathrm{K}_{\mathrm{e}}$ Vs CGR curves are drawn for second stage of crack growth rate given by Figure 3 and 4 . Lines of best fit have been drawn, from each set of readings, from which CGR constants were evaluated for different models as below:

1. Paris model: - A decrement in the value of constant $m$ is observed. Constant $\mathrm{C}$ was found to have a little variation.

2. Elber model: - The values of constant $m$ were found to be nearly equal to the values of its counterpart in Paris model. The values of constant $\mathrm{C}$ are found to increase if we compare them with that of the Paris model, which are constant. 
3. Walker model: - The values of constant $m$ have the same variation as it is in Paris and Elber model, but they are somewhat less in comparison to that of Paris model. The values of constant $\mathrm{C}$ are having very low variation almost negligible. Constant $n$ increased consistently.

4. Foreman model: - The values of constant $m$ are equal to the values of constant $\mathrm{m}$ in Paris model. Constant $\mathrm{C}$ is high in comparison to the values of $\mathrm{C}$ in other models.

(B) Load range constant: From Figure 5 and 6 this was observed that with increasing load ratio life of components \& crack initiation stage decreased while the crack growth rate is found to increase.

$\Delta K$ Vs CGR \& $\Delta$ Ke Vs CGR curves were drawn for second stage of crack growth rate given by Figure 7 and 8 . Lines of best fit have been drawn from each set readings, from which CGR constants were evaluated of different models as below:

1. Paris model: - Constants $m$ are found to have very low variations and constant $\mathrm{C}$ are found to decrease steadily.

2. Elber model: - In this model the value of constant $m$ have been found to have very low variation, for analysis purpose its value may be taken as constant. The value of constant $\mathrm{C}$ decreased consistently.

3. Walker model: - It shows that the value of constant $m$ has little variation, and is less in comparison to other models. The constant $C$ was found to decrease continuously. Exponent $\mathrm{n}$ has steady increment.

4. Foreman model: - In this model the value of constant $m$ is same as that of Paris model. Value of $C$ decreased consistently, it has higher values in comparison to other models. 


\subsection{Relationship of CGR constants}

After evaluating the crack growth rate constants of different models a relationship was developed involving constant $C$ and constant $m$. The constant $m$ is found to have a relationship with stress range $\Delta \sigma$, constant $C$ bears a relationship with maximum stress $\sigma_{\mathrm{m}}$. Relationship of $\mathrm{C}$ and $\sigma_{\mathrm{m}}$ can be expressed in the form as follows:

$$
\sigma_{m}+S_{1}(\log C)+S_{2}=0
$$

Here $s_{1} \& s_{2}$ are constants which were evaluated by drawing the curve between maximum stress $\sigma_{\mathrm{m}} \&$ constant $\mathrm{C}$ on semi log scale for each model.

Relationship between stress range $\Delta \sigma$ and constant $\mathrm{m}$ is found to be as follows:

$$
\Delta \sigma+T_{1}(m)+T_{2}=0
$$

Again $T_{1} \& T_{2}$ are constants which are evaluated by drawing the curve between stress range $\Delta \sigma$ and constant $m$ on linear scale. Constants $T_{1}, T_{2}, S_{1}$ and $S_{2}$ are given in chapter four.
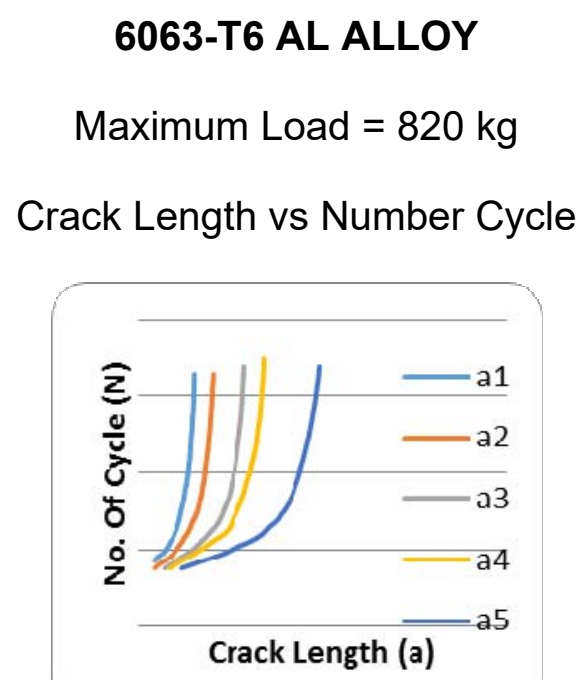

Figure 1: Number of Cycles Vs Crack Length

\begin{tabular}{|c|c|c|c|c|c|}
\hline TEST & S1 & S2 & S3 & S4 & S5 \\
\hline R & 0 & 0.2 & 0.3 & 0.35 & 0.45 \\
\hline
\end{tabular}

[http://creativecommons.org/licenses/by/3.0/us/]

Licensed under a Creative Commons Attribution 3.0 United States License 

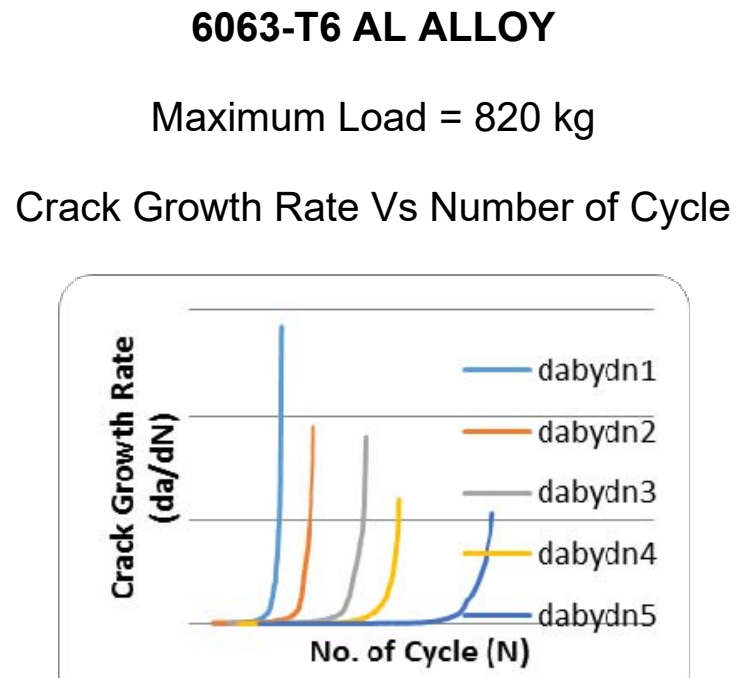

Figure 2: Number of Cycles Vs Crack Growth Rate

\begin{tabular}{|c|c|c|c|c|c|}
\hline Test & S1 & S2 & S3 & S4 & S5 \\
\hline$R$ & 0 & 0.2 & 0.3 & 0.35 & 0.45 \\
\hline
\end{tabular}

6063-T6 AL ALLOY

Maximum Load $=820 \mathrm{~kg}$

Log Crack Growth Rate Vs Log Stress Intensity Range

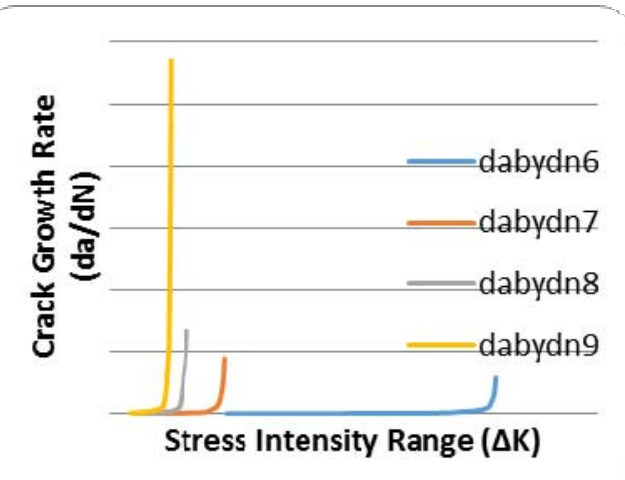

Figure 3: Stress Intensity range Vs Crack Growth Rate

\begin{tabular}{|c|c|c|c|c|c|}
\hline Test & S1 & S2 & S3 & S4 & S5 \\
\hline$R$ & 0 & 0.2 & 0.3 & 0.35 & 0.45 \\
\hline$U$ & .69 & .79 & .84 & .87 & .93 \\
\hline
\end{tabular}

6063-T6 AL ALLOY

Maximum load $=820 \mathrm{~kg}$

Log Ccrack Growth Rate Vs Log Effective Stress Intensity Range

[http://creativecommons.org/licenses/by/3.0/us/]

Licensed under a Creative Commons Attribution 3.0 United States License 


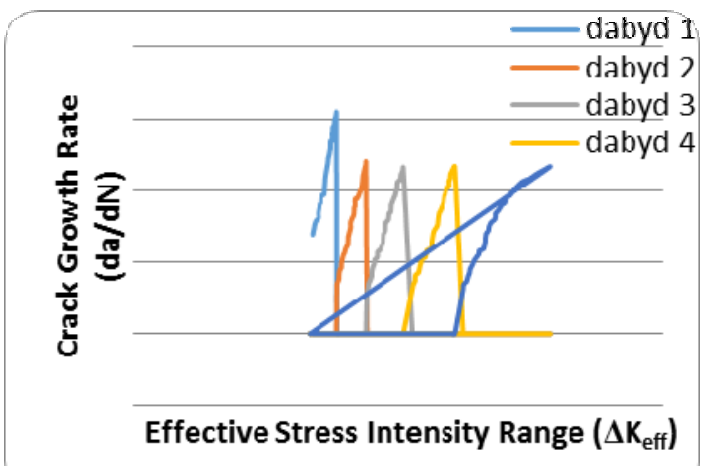

Figure 4: Effective Stress Intensity range Vs Crack Growth Rate

\begin{tabular}{|c|c|c|c|c|c|}
\hline Test & S1 & S2 & S3 & S4 & S5 \\
\hline R & 0 & 0.2 & 0.3 & 0.35 & 0.45 \\
\hline
\end{tabular}

6063-T6 AL ALLOY

Load range $=585 \mathrm{~kg}$

Crack Length Vs Number of Cycle

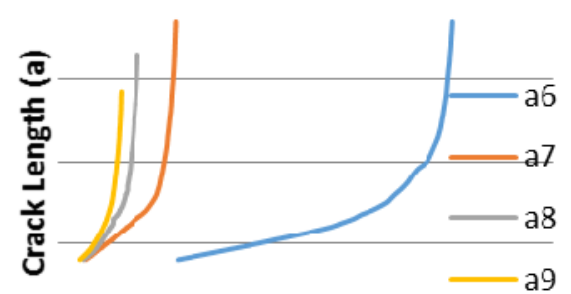

No. of Cycle (N)

Figure 5: Number of Cycles Vs Crack Length

\begin{tabular}{|c|c|c|c|c|}
\hline Test & S6 & S7 & S8 & S9 \\
\hline R & 0 & 0.2 & 0.4 & 0.6 \\
\hline
\end{tabular}

6063-T6 AL ALLOY

Load Range $=585 \mathrm{~kg}$

Crack Growth Rate Vs Number of Cycle 


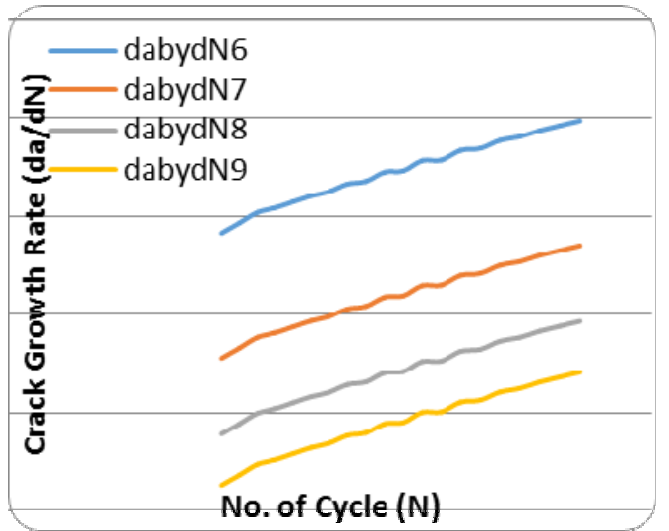

Figure 6: Number of Cycles Vs Crack Growth Rate

\begin{tabular}{|c|c|c|c|c|}
\hline TEST & S6 & S7 & S8 & S9 \\
\hline R & 0 & 0.2 & 0.4 & 0.6 \\
\hline
\end{tabular}

6063-T6 AL ALLOY

Load Range $=585 \mathrm{~kg}$

Log Crack Growth Rate Vs Log Stress Intensity Range

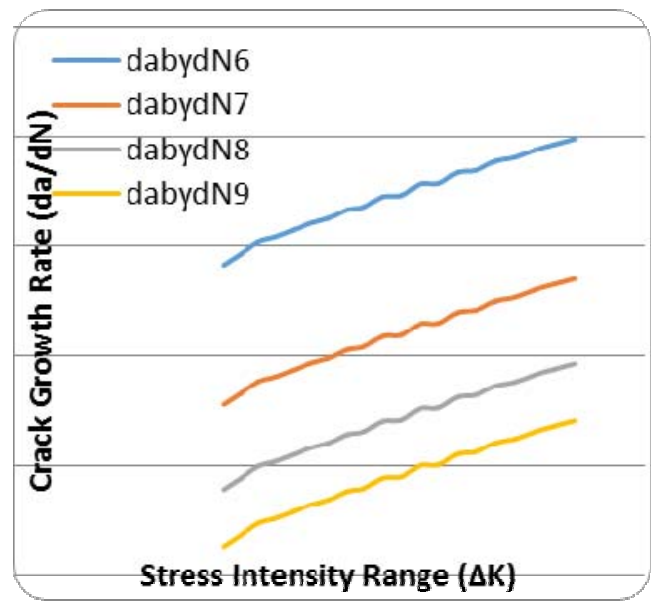

Figure 7: Stress Intensity range Vs Crack Growth Rate

\begin{tabular}{|c|c|c|c|c|}
\hline Test & S6 & S7 & S8 & S9 \\
\hline R & 0 & 0.2 & 0.4 & 0.6 \\
\hline
\end{tabular}

\section{3-T6 AL ALLOY}

Load Range $=585 \mathrm{~kg}$

Log Crack Growth Rate Vs Log Effectivestress Intensity Range 


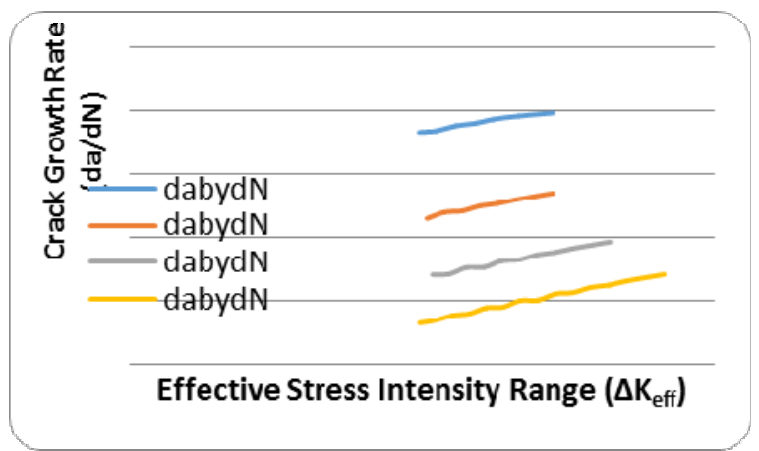

Figure 8: Effective Stress Intensity range Vs Crack Growth Rate

\begin{tabular}{|c|c|c|c|c|}
\hline Test & S6 & S7 & S8 & S9 \\
\hline R & 0 & 0.2 & 0.4 & 0.6 \\
\hline$U$ & .69 & .79 & .90 & 1.03 \\
\hline
\end{tabular}

\section{RESULTS \& DISCUSSION}

To evaluate constants $C \& m$ the maximum stress $V s$ log $C$ and stress range $V s$ m curves were used.

Constant $\mathrm{C}$ was plotted on log scale with maximum stress on linear scale. Slopes \& intercepts give constants $S_{1}$ and $S_{2}$ respectively. Straight line passing through maximum number of points has been drawn for each model. Slope of the lines gives constant $T_{1} \&$ intercepts of the lines gives constant $T_{2}$. The constants evaluated are given in Table no (4) for different models.

Table no 4: Constants for 6063-T6 Al Alloy

\begin{tabular}{|c|c|c|c|c|}
\hline \multirow{2}{*}{ Model } & \multicolumn{2}{|c|}{$\sigma_{w \mathrm{x}}+S_{1}(\log C)+S_{2}=0$} & \multicolumn{2}{c|}{$\Delta \sigma+T_{1}(m)+T_{22}=0$} \\
\cline { 2 - 5 } & Constant $\mathrm{S}_{1}$ & Constant $\mathrm{S}_{2}$ & Constant $\mathrm{T}_{1}$ & Constant $\mathrm{T}_{2}$ \\
\hline Paris & 3.70 & 30.85 & -3.25 & 6.49 \\
\hline Elber & 2.95 & 21.89 & -3.46 & 7.19 \\
\hline Walker & 3.11 & 25.29 & -2.08 & 1.68 \\
\hline Foreman & 4.18 & 6.66 & -3.25 & 6.49 \\
\hline
\end{tabular}

\section{CONCLUSIONS}

Variation in load range affects the crack growth rate constant $m$, i.e. constant $m$ had the higher variation when load range was varying. For constant load range its variation was negligible constant $\mathrm{C}$ was almost constant at variable load range. 
DOI: 10.14807/ijmp.v6i4.343

Variation of maximum load affects constant $C$, i.e. constant $C$ in found to vary with maximum load. At constant maximum load it is found to be almost constant.

Walker model modifies the constants $m$ of Paris model, by introducing a new constant $n$. This constant $n$ is the exponent of maximum stress intensity $K_{m}$ modification introduced in constant $\mathrm{C}$ is negligible.

Foreman model modifies the constant $\mathrm{C}$ of Paris model by introducing the fracture toughness $\mathrm{K}_{\mathrm{f}}$ of the material. It does not affect constant $\mathrm{m}$.

Elber model introduces a slight modification in Paris model for both constants $\mathrm{C}$ $\& m$.

\section{REFERENCES}

ASTM (1967) Recommended Practice for Plane Strain Fracture Toughness Testing of High strength Metallic Materials Using a Fatigue Cracked Bend Specimen", TRP prepared by ASTM committee E-24.

ASTM (1976) Standard Definition of terms Relating to Fatigue Testing \& Statistical Analysis of Data, ASTM STP, n. 595, p. 61-77.

BROEK, D. (1982) Elementary Engg. Fracture Mechanics, Martinus Nijhoff Publishers, London.

ELBER, W. (1970) Fatigue Crack Closure-Under Cyclic Tension, Engg. Fracture Mechanics, n. 2, p. 37-45.

ELBER, W. (1971) The Significance of Fatigue Crack Closure, ASTM, n. 486, p. 230242, 1971.

FOREMAN, R. G.; MEARNEY, V. E.; ENGLE, R. M. (1967) Numerical Analysis of Crack Propagation in Cyclic Loaded Structures", J.I. Basic Engg., Trans. ASME, Sr. D. n. 89, p. 454.

KUMAR, R.; GARG, S. B. L. (1988a) Effect of Stress Ratio on Effective Stress Ratio \& Crack Growth in 6061-T6 Aluminium Alloy, Int. J., Pres. Ves. and piping.

KUMAR, R.; GARG, S. B. L. (1988b) Study of Crack Closure Under Constant Amplitude Loading for 6063-T6 Aluminium Alloy, Int. J. Press. Ves.and piping.

NICCOLLS, E. H. (1976) A Co-relation for Fatigue Crack Growth Rate, ScriptaMetall, n. 10 , p. 295-298.

OSGOOD, C. C. (1982) Fatigue Design Cranbury, New Jersey, U.S.A., Pergamon Press.

PANDEY, A. K. (1988) Effect of Load Parameters on Crack Growth Rate \& Fatigue Life, M.E. thesis, Allahabad. 
PARIS, P. C.; ERDOGAN, F. (1963) A Critical Analysis of Crack Propagation Laws, Trans .ASME J. Basic Engg. n. 55, p. 528-534.

PEARSON, S. (1972) Effect of Mean Stress in Aluminum Alloy in High \& low Fracture Toughness, Engg. Fracture Mechanics, n. 4, p. 9-24.

VIKRAM, N.; AGRAWAL, S.; KUMAR, R. (2014) Effect of Strain Hardening on Fatigue Crack Growth in5052 Al Alloy for Constant Amplitude Loading" SYLWAN., v. 158, n. 6, p. 110-124.

VIKRAM, N.; KUMAR, R. (2013) Review on Fatigue Crack Growth and Finite Element Method." IJSER, v. 4, n. 4,p. 833-842.

VIKRAM, N.; KUMAR, R. (2015) Effect of Strain Hardening On Fatigue Crack Closure In Aluminum Alloy, Int. J. Engg. Res. \& Sci. \& Tech, v. 4, n.3.

WALKER, K. (1970) The Effect of Stress Ratio During Crack Propagation \& Fatigue for 2024-T3 and 7075-T6 aluminium, ASTM STP, n. 462, p. 1-14.

ZHENG, X. (1983) Fatigue Crack Propagation in Steels, Engg. Fracture Mechanics, $n$. 18 , p. $965-973$. 


\section{APPENDIX A}

\section{Symbols}

a

A

B

C

$d 1, d 2, d 3 \ldots d 7$

$\frac{d a}{d N}$

D

$E$

f

$\mathrm{K}$

$\mathrm{K}_{\mathrm{C}}$

$\mathrm{K}_{\mathrm{m}}$

$\mathrm{K}_{\mathrm{n}}$

$\mathrm{K}_{\mathrm{o}}$

$\mathrm{K}_{\mathrm{t}}$

$\Delta \mathrm{K}$

$\Delta \mathrm{K}_{\ominus}$

m

$\mathrm{n}$

$\mathrm{N}$

$\mathrm{N}_{\mathrm{f}}$

$N_{p}$

$\mathrm{p}$

\section{Description}

Crack length

A constant

Specimen thickness

Constant of crack growth equation

Constants of seven point method

Crack growth rate

A constant

Young's modulus of elasticity

A variable factor

Stress intensity factor

Fracture toughness of the material

Maximum stress intensity factor of a cycle

Minimum stress intensity factor of a cycle

Optimum stress intensity factor of a cycle

Threshold stress intensity factor

Stress intensity range

Effective stress intensity range

Exponent of crack growth rate equation

Exponent of crack growth rate equation

Number of cycles

Number of cycles to failure

Number of readings in a set of readings

A ratio $\frac{\Delta \theta}{\Delta y}$ 
ISSN: 2236-269X

DOI: 10.14807/ijmp.v6i4.343

$\mathrm{P}$

$\mathrm{P}_{\mathrm{a}}$

$P_{m}$

$\mathrm{P}_{\mathrm{n}}$

$\Delta \mathrm{P}$

$\mathrm{R}$

$\mathrm{S}_{1}$

$\mathrm{S}_{2}$

$\mathrm{T}_{1}$

$\mathrm{T}_{2}$
Simple load

Average load in a cycle

Maximum load in a cycle

Minimum load in a cycle

Load range in a CAL cycle

Stress ratio in CAL cycle $\left(\frac{P_{m}}{B_{n}}\right)$

Relationship constant

Relationship constant

Relationship constant

Relationship constant 